\title{
Development of monocyte Toll-like receptor 2 and Toll-like receptor 4 in preterm newborns during the first few months of life
}

\author{
Chung-Min Shen ${ }^{1,2}$, Shih-Chang Lin ${ }^{3}$, Dau-Ming Niu ${ }^{1,4}$ and Yu Ru Kou ${ }^{5}$
}

BACKGROUND: Although the immaturity of Toll-like receptor 2 (TLR2) and Toll-like receptor 4 (TLR4) at birth in preterm newborns is known, their development during the first few months of life remains unclear.

METHODS: Blood monocytes of preterm newborns (gestational age: $24-36$ wk) were obtained every 2 wk when possible in order to perform serial measurements of TLR2 and TLR4 surface expression, as well as lipopolysaccharide (LPS)-induced cytokine production. Measurements using monocytes from term newborns and adults were also performed.

RESULTS: The monocytes of preterm newborns obtained at birth displayed reduced surface expression of TLR2 and TLR4, and diminished responses of tumor necrosis factor-a (TNF-a) and interleukin (IL)-8 to LPS stimulation. Regardless of gestational age, monocyte expression of TLR2 and TLR4 in preterm newborns increased rapidly within the first 2 wk after birth, quickly reaching those of term newborns. These increases continued for the following 4-6wk, although the increase began to plateau. By contrast, LPS-induced production of TNF-a and IL-8 did not elevate over this period in preterm newborns.

CONCLUSION: The blood monocytes of preterm newborns display rapid increase in TLR2 and TLR4 expression during the first few months of life, whereas LPS-induced cytokine production functionality did not improve in parallel.

P reterm newborns are known to be highly vulnerable to bacterial infection during the first few months after birth $(1,2)$. The high susceptibility to bacterial infection in these neonates has been attributed mainly to the immaturity of their innate immune system, including their Toll-like receptors (TLRs) (3-5). TLRs, a family of pathogen-recognition receptors that recognize the highly conserved and essential molecular structures of microbes, are known to play an important role in innate immunity in response to bacterial infection (6,7). Among TLR members, TLR2 and TLR4 are the cell-surface receptors that recognize cell wall components of Gram-positive and Gramnegative bacteria, respectively $(6,7)$. Stimulation of TLRs by ligands of microbial origin results in activation of a wide array of signaling pathways, leading to various responses that are important to both inflammation and the induction of adaptive immunity $(6,7)$. Therefore, it seems likely that the immaturity of the TLRs is closely associated with the high risk of sepsis in preterm newborns $(1,5)$.

Clinical (8-12) and animal studies (13-15) indeed have shown reduced expression of TLR2 and TLR4, as well as diminished function in cytokine production induced by their agonists at birth, in preterm newborns. However, deficiencies in the TLR system at birth do not necessarily mean that it does not improve during the early postnatal period. For this reason, much attention has been paid recently to the postnatal development of TLRs. Some studies have investigated the changes in cytokine responses of monocytes to TLR agonists during the first year after birth (16-19), whereas others have focused on the changes that occur in the few years after birth $(2,16,20,21)$ in neonates. However, these studies were performed mainly, if not entirely, using data from full-term newborns. Accordingly, our knowledge is limited regarding the development of TLRs during the first few months after birth in preterm newborns, the most critical period for sepsis in this group.

The aim of this study was to investigate the development of TLR2 and TLR4 expression and to assess the functionality of lipopolysaccharide (LPS)-induced cytokine production by blood monocytes of preterm newborns during the first few months after birth. To accomplish these objectives, monocytes were collected every $2 \mathrm{wk}$ after birth whenever possible to allow serial measurements using the same study cohort.

\section{RESULTS}

\section{Subject Characteristics}

Table 1 shows the clinical characteristics of the three study groups. As shown, the mean gestational age, birth body weight, first-minute Apgar score, fifth-minute Apgar score, and sex ratio of the preterm newborns $(n=62)$ were all significantly different from those of the healthy full-term neonates $(n=93)$. The cell counts for total leukocytes, neutrophils, lymphocytes, and monocytes in the preterm group did not significantly 
differ from those of the full-term group. In addition, the cell counts in both newborn groups were higher than those in the adult group (Table 1), a result that is similar to that reported by other investigators (22). Furthermore, there was no significant

Table 1. Characteristics of the subjects in the three study groups

\begin{tabular}{|c|c|c|c|}
\hline & Preterm $(n=62)$ & Full-term $(n=93)$ & Adult $(n=17)$ \\
\hline BBW (range) (g) & $\begin{array}{c}1,562.82 \pm 489.11 \\
(622-2,460)\end{array}$ & $\begin{array}{c}3,157.31 \pm 367.43 \\
(2,521-4,319)\end{array}$ & - \\
\hline GA (range) (wk) & $\begin{array}{c}30.58 \pm 3.18 \\
(24-36)\end{array}$ & $\begin{array}{c}38.55 \pm 0.96 \\
(37-41)\end{array}$ & - \\
\hline $\begin{array}{l}\text { Apgar score } \\
\text { (first minute) }\end{array}$ & $6.1 \pm 2.4$ & $7.9 \pm 2.3$ & - \\
\hline $\begin{array}{l}\text { Apgar score } \\
\text { (fifth minute) }\end{array}$ & $7.6 \pm 2.9$ & $8.7 \pm 3.1$ & - \\
\hline Sex (male/female) & $38 / 24^{*}$ & $42 / 51^{*}$ & $14 / 3$ \\
\hline \multicolumn{4}{|c|}{ Blood count and biomarkers on admission } \\
\hline $\begin{array}{l}\text { Leukocytes } \\
\text { (cells } / \mathrm{mm}^{3} \text { ) }\end{array}$ & $15,792 \pm 3,416^{*}$ & $17,438 \pm 2,912^{*}$ & $5,874 \pm 1,109$ \\
\hline $\begin{array}{l}\text { Neutrophils } \\
\left(\text { cells } / \mathrm{mm}^{3} \text { ) }\right.\end{array}$ & $10,294 \pm 2,413^{*}$ & $11,432 \pm 1,678^{*}$ & $2,972 \pm 895$ \\
\hline $\begin{array}{l}\text { Lymphocytes } \\
\text { (cells } / \mathrm{mm}^{3} \text { ) }\end{array}$ & $6,741 \pm 1,277^{*}$ & $5,423 \pm 1,211^{*}$ & $2,871 \pm 912$ \\
\hline $\begin{array}{l}\text { Monocytes } \\
\text { (cells } / \mathrm{mm}^{3} \text { ) }\end{array}$ & $1,688 \pm 413^{*}$ & $1,461 \pm 398^{*}$ & $563 \pm 122$ \\
\hline $\mathrm{CRP}(\mathrm{mg} / \mathrm{dl})$ & $0.09 \pm 0.06$ & $0.13 \pm 0.02$ & $0.24 \pm 0.14$ \\
\hline
\end{tabular}

There was no significant difference in data between the preterm and full-term groups. Data are presented as means \pm SD.

BBW, birth body weight; CRP, C-reactive protein; GA, gestational age.

${ }^{*} P<0.05$ vs. the adult group.
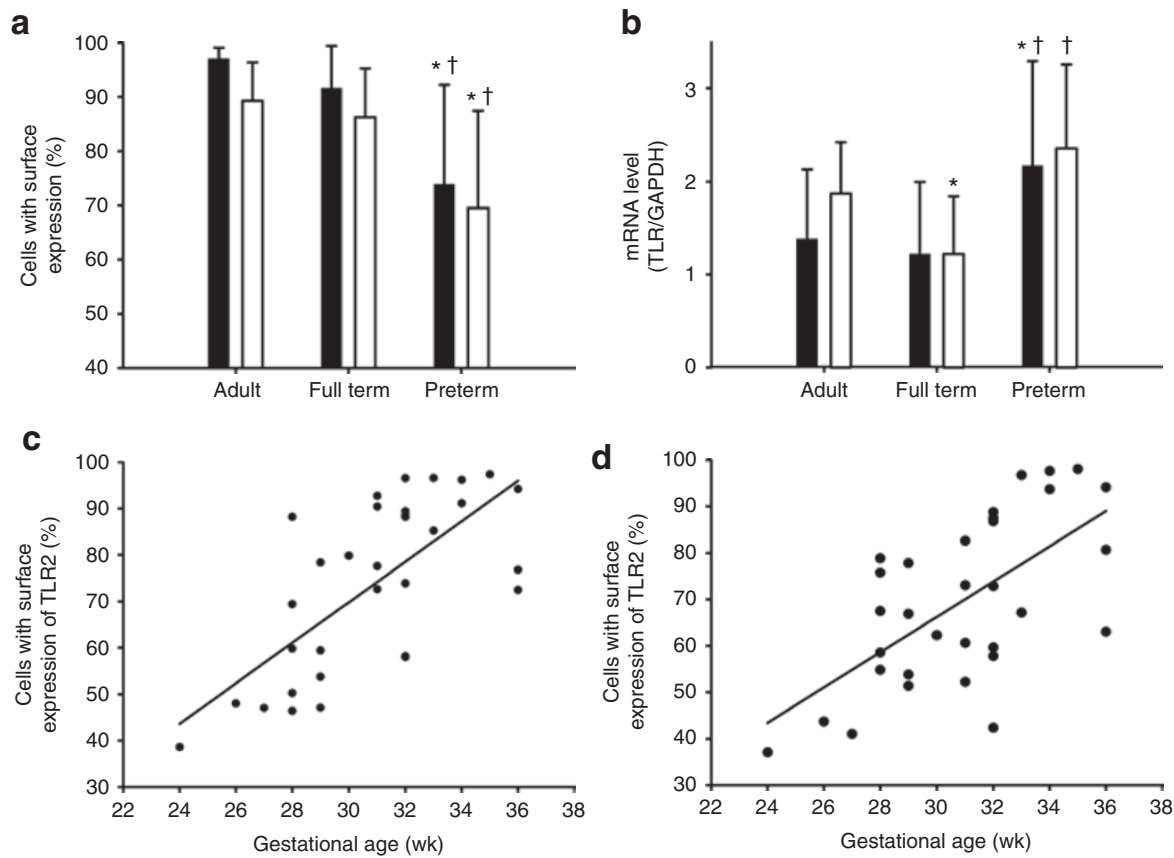

Figure 1. Expression of surface protein and mRNA of TLR2 and TLR4 on blood monocytes obtained from preterm newborns with various gestational ages. The surface protein expression was measured using antihuman monoclonal antibodies and immunofluorescence flow cytometry. The mRNA levels were measured by real-time PCR. ( $(\mathbf{a}$ and $\mathbf{b}$ ) Mean values of surface and mRNA expression of TLR2 (black bars) and TLR4 (white bars) of preterm newborns ( $n=32$ ) were compared with those of healthy term newborns $(n=71)$ and of healthy adults $(n=17)$. Data are mean \pm SD. ${ }^{*} P<0.05$ vs. the adult group; ${ }^{\dagger} P<0.05$ vs. the full-term group. (c and $\mathbf{d}$ ) The expression levels of surface protein of TLR2 and TLR4 of the preterm newborns were positively correlated with their gestational age. The regression line in $\mathbf{c}(y=4.36 x-61.11)$ has a correlation coefficient of 0.71 , and the regression line in $\mathbf{d}(y=3.80 x-47.66)$ has a correlation coefficient of 0.64 . TLR, Toll-like receptor. 
a
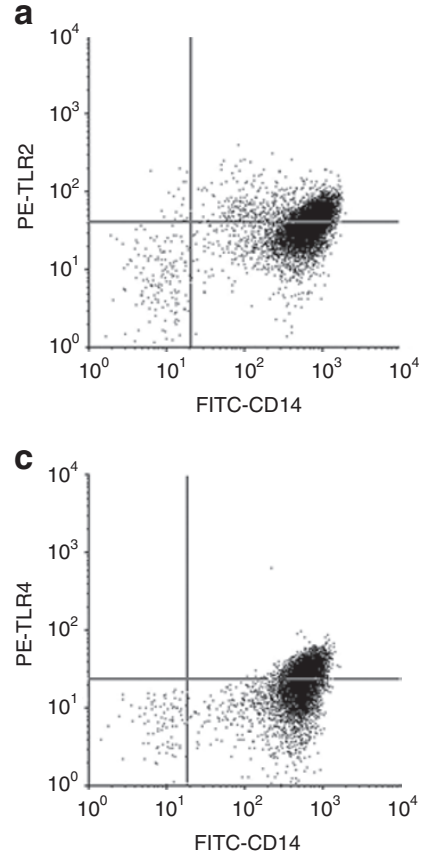

b

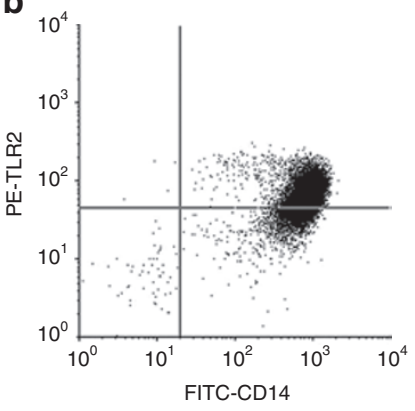

d

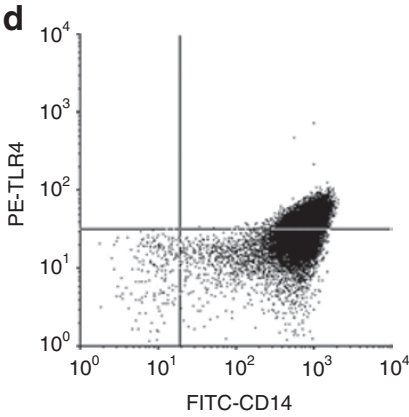

Figure 2. Dot plots from flow cytometry analysis showing surface expression of (a and $\mathbf{b})$ TLR2 and (c and $\mathbf{d}$ ) TLR4 on blood monocytes obtained from a preterm newborn with a gestational age of $26 \mathrm{wk}$. a and c: Cord blood monocytes obtained immediately after birth (TLR2: 48.04\%; TLR4: 43.72\%). b and d: Blood monocytes obtained $2 \mathrm{wk}$ after birth (TLR2: 74.28\%; TLR4: 69.82\%). Monocytes were identified by additional staining with anti-CD14 monoclonal antibody. Cells were stained with an isotype antibody (PE- or fluorescein isothiocyanate-labeled mouse immunoglobulin G2a). Note that the expression increased rapidly during the $2 \mathrm{wk}$ after birth. PE, phycoerythrin; TLR, Toll-like receptor.

26-32 wk) when possible. Figure 2 shows representative data of flow cytometric analysis from one preterm newborn (gestational age: $26 \mathrm{wk}$ ), which demonstrates a rapid increase in the percentage of TLR2-positive and TLR4-positive monocytes within the first $2 \mathrm{wk}$ after birth. Regardless of gestational age, this rapid postnatal development of monocyte TLR2 and TLR4 expression was observed in each of the nine preterm newborns (Figure 3$)$. As a group $(n=9)$, the percentages of TLR2positive and TLR4-positive monocytes impressively increased from their baselines of $60.5 \pm 14.1 \%$ (TLR2) and $58.3 \pm 15.0 \%$ (TLR4) to levels of $84.9 \pm 8.4 \%$ (TLR2) and $82.4 \pm 9.4 \%$ (TLR4) within the first $2 \mathrm{wk}$ after birth. At this time point, the TLR2 and TLR4 expression levels were not significantly different from those of full-term newborns (TLR2: $91.7 \pm 7.7 \%$; TLR4: $86.0 \pm 9.0 \% ; n=71$ ) but were still significantly different from those of adults (TLR2: $97.1 \pm 2.0 \%$; TLR4: $89.3 \pm 7.1 \%$; $n=17$ ). This increase in the percentage of TLR2- and TLR4-positive monocytes continued at 4 and $6 \mathrm{wk}$ after birth, although the increase began to plateau (Figure 3 ).

Diminished Monocyte Function of LPS-Induced Cytokine Production in Preterm Newborns Immediately After Birth

Cord blood monocytes were isolated immediately after birth from preterm newborns ( $n=30$; gestational age: $30.3 \pm 3.5 \mathrm{wk}$; range: $24-36 \mathrm{wk})$ and from full-term newborns $(n=22$;
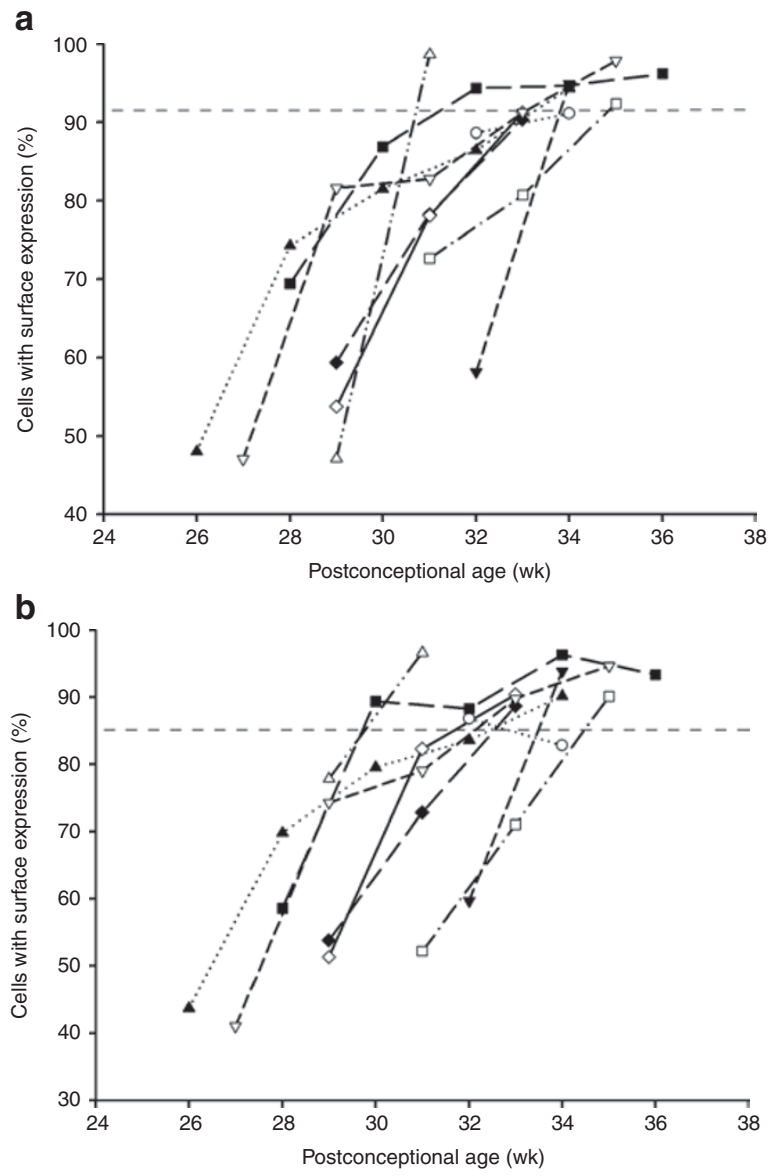

Figure 3. Rapid increase in the surface expression of (a) TLR2 and (b) TLR4 by blood monocytes during the first 2 mo of life in nine preterm newborns. Series measurements for every $2 \mathrm{wk}$ after birth were carried out in each newborn. Each symbol represents data from one individual case. Dashed line represents the mean level of expression of TLR2 or TLR4 in full-term newborns as shown in Figure 1a. The preterm newborns have an average gestational age of $29.6 \pm 2.3 \mathrm{wk}(n=9)$. Note that regardless of gestational age, the expression in preterm newborns was low at birth but rapidly increased to reach the mean levels of full-term newborns within 2 wk after birth. TLR, Toll-like receptor.

gestational age: $38.9 \pm 0.7 \mathrm{wk}$; range: $38-40 \mathrm{wk})$. It was found that the increases in production of tumor necrosis factor- $\alpha$ (TNF- $\alpha$ ) and interleukin (IL)-8 after LPS induction by monocytes collected immediately after birth in preterm newborns $(0 \mathrm{~d}$ culturing) were significantly lower than those of full-term newborns (Figure 4$)$ and were positively correlated $(P<0.05)$ with gestational age (Figure 5). This hyposecretion of TNF- $a$ and IL- 8 was also observable in monocytes of preterm newborns after 3 and $5 \mathrm{~d}$ of culturing (Figure 4 ).

\section{Postnatal Development of Monocyte Function of LPS-Induced} Cytokine Production in Preterm Newborns

Serial samples of peripheral blood were taken every $2 \mathrm{wk}$ in 15 of the 30 preterm newborns (gestational age: $28.3 \pm 2.9 \mathrm{wk}$; range: $24-32 \mathrm{wk}$ ) when routine blood tests were required. It was found that the LPS-induced production of TNF- $\alpha$ and IL-8 did not significantly change over a period that lasted up to 8 wk after birth (Figure 6). 
a
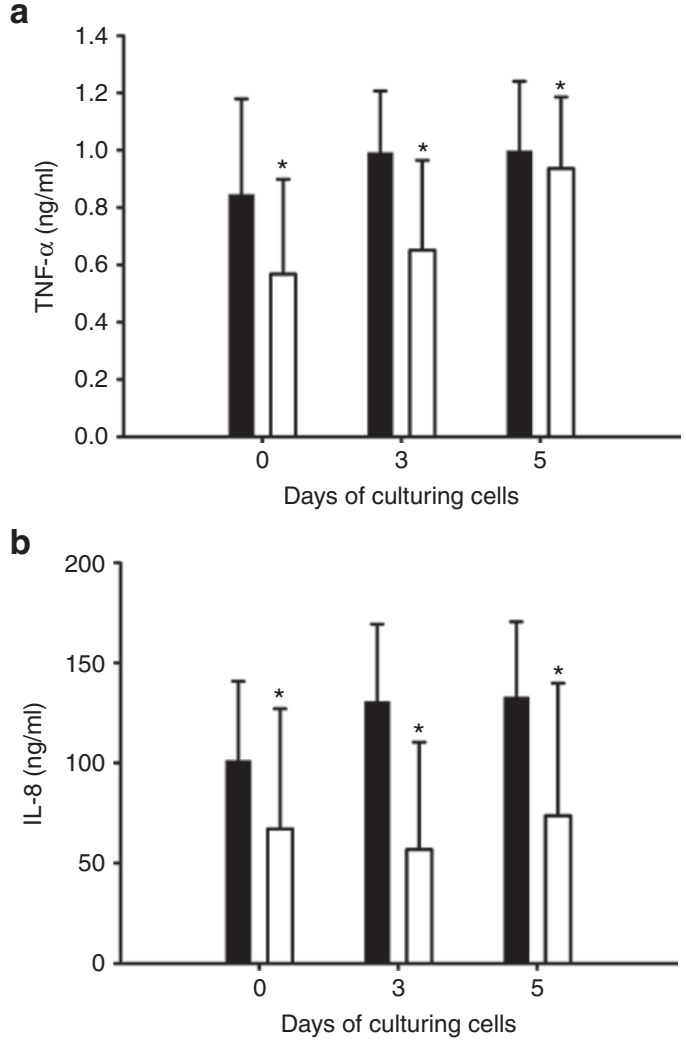

Figure 4. Comparisons of lipopolysaccharide (LPS)-induced cytokine production by blood monocytes in preterm (white bars) and full-term newborns (black bars). Blood monocytes were cultured in cell medium for 0,3 , and $5 \mathrm{~d}$ after birth and stimulated with LPS. Concentrations of (a) TNF- $\alpha$ and (b) IL-8 were measured by enzyme-linked immunosorbent assay. The preterm $(n=30)$ and full-term newborns $(n=22)$ had average gestational ages of $30.3 \pm 3.5$ and $38.9 \pm 0.7 \mathrm{wk}$, respectively. Data are mean $\pm S D$. ${ }^{*} P<0.05$ vs. the full-term group. IL, interleukin; TNF, tumor necrosis factor.

\section{DISCUSSION}

This study reports three major findings. First, our results show that the blood monocytes of preterm newborns obtained at birth displayed reduced surface expression of TLR2 and TLR4 and diminished response to LPS stimulation with respect to TNF- $\alpha$ and IL-8 (Figures 1 and 4). Second, we demonstrate for the first time that, regardless of gestational age, the monocyte surface expression of TLR2 and TLR4 in preterm newborns increases rapidly within the first few weeks after birth to reach levels that are close to those of full-term newborns and adults (Figure 3). Third, in contrast to the rapid development of TLR2 and TLR4 expression, the LPS-induced production of TNF- $\alpha$ and IL- 8 by the monocyctes of these neonates does not elevate significantly over this early postnatal period (Figure 6).

Our first major finding is in line with previous reports (8-15) regarding the immaturity of TLR2 and TLR4 at birth. In fact, this concept of immaturity of the TLR system has been frequently used to explain the high susceptibility of preterm newborns to bacterial infection (3-5). We also found that, unlike the situation of surface protein expression, the mRNA expression of monocyte TLR2 and TLR4 in the preterm newborns was not reduced. Previous studies have reported that an
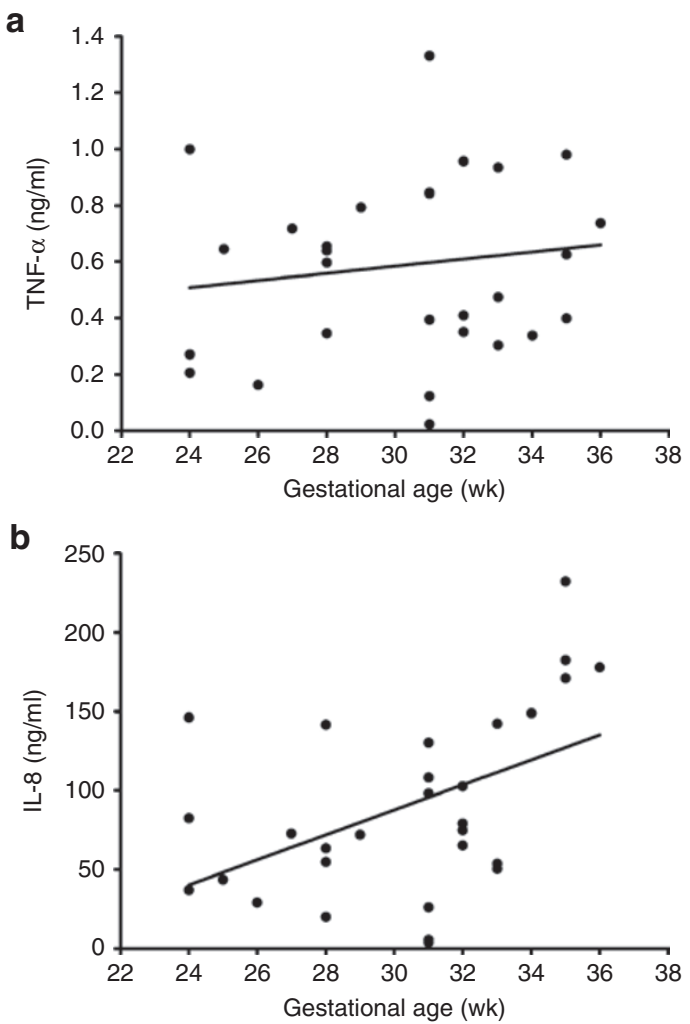

Figure 5. Correlation of gestational age with lipopolysaccharide (LPS)-induced cytokine production by blood monocytes in preterm newborns. Blood monocytes were cultured in cell medium immediately after birth and stimulated with LPS. Concentrations of (a) TNF- $a$ and (b) IL-8 in the cell culture supernatants $24 \mathrm{~h}$ after LPS stimulation were measured by enzyme-linked immunosorbent assay. The regression line in $\mathbf{a}(y=0.01 x+0.20)$ has a correlation coefficient of 0.14 , and the regression line in $\mathbf{b}(y=7.90 x-149.40)$ has a correlation coefficient of 0.48 . The preterm newborns $(n=30)$ are the same as those investigated and shown in Figure 4. IL, interleukin; TNF, tumor necrosis factor.

increase in monocyte expression of TLR mRNA does not necessarily lead to a corresponding increase in TLR proteins (23). Therefore, our data suggest that the reduced surface expression of TLR2 and TLR4 may be due to defects in the posttranscriptional and/or posttranslational regulation $(24,25)$. To this end, it is known that both the internal and external environments of these neonates undergo dramatic changes immediately after birth (26). Therefore, the speed of maturation of the TLR system during the first few months after birth in preterm newborns is critical to the development of their innate host defenses against bacterial infection. In agreement with this, Yerkovich et al. (16) found a reduction in the responses to LPS stimulation with respect to TNF- $\alpha$, IL- 6 , and IL-10 by blood monocytes collected at birth as compared with those collected at 2 mo after birth in two groups of newborns. Furthermore, Nguyen et al. (18) compared the agonist responses of TLR4 or TLR9 produced by monocytes and dendritic cells among different age groups (0-, 3-, 6-, 9-, and 12-mo-old infants) of infants and found that the production of several cytokines displayed an age-dependent upregulation, whereas production of others reduced over time. Burl et al. (19) investigated the 

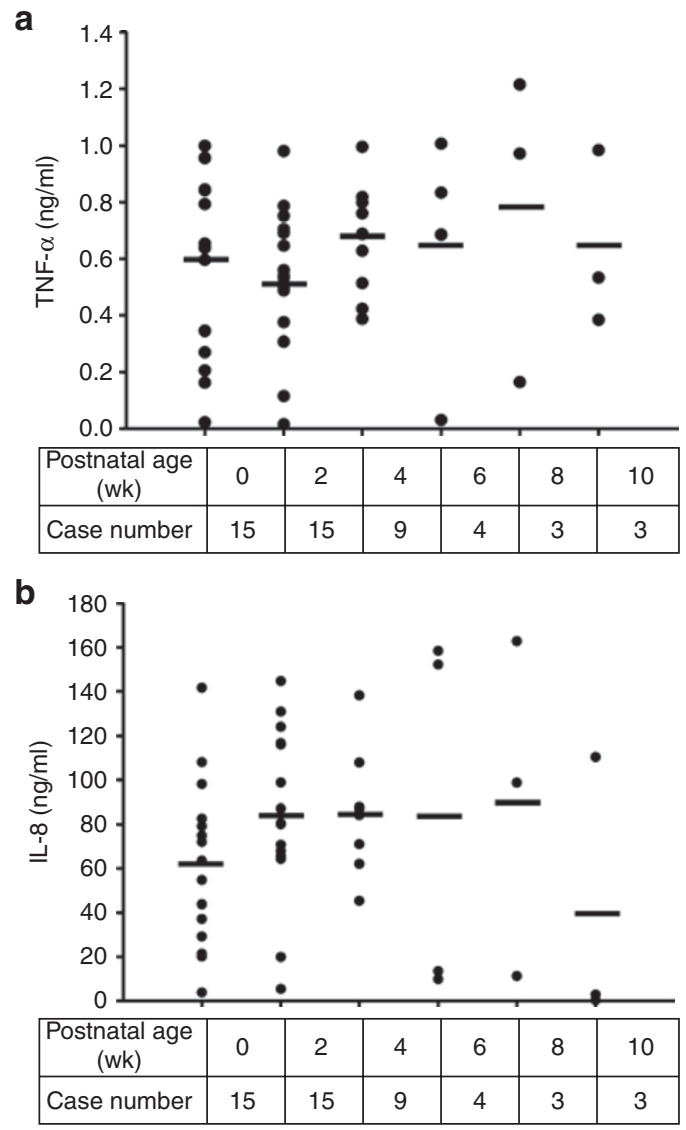

Figure 6. Series measurements of lipopolysaccharide (LPS)-induced cytokine production from blood monocytes in preterm newborns. Blood monocytes were obtained every 2 wk after birth for up to 8 wk, cultured in cell medium, and immediately stimulated with LPS. Concentrations of (a) TNF- $a$ and (b) IL-8 in the cell culture supernatants $24 \mathrm{~h}$ after LPS stimulation were measured by enzyme-linked immunosorbent assay. The initial case number was 15 preterm newborns, who had an average gestational age of $28.3 \pm 2.9 \mathrm{wk}$. Each dot indicates data from one case, and the horizontal bars indicate mean values of the group. Note that, unlike the rapid increase in the expression of TRL2 and TLR4, the LPS-induced cytokine production did not improve during the 10 -wk postnatal period. IL, interleukin; TLR, Toll-like receptor; TNF, tumor necrosis factor.

response of monocytes to TLR1-9 agonists in terms of various cytokines using eight groups of neonates of different ages; they found that each cytokine studied demonstrated a distinct agedependent profile in response to each TLR agonist during the first year of life. Because these studies were performed mainly, if not entirely, using full-term neonates, the generalizability of these observations to the population of preterm newborns is limited. In addition, no study has focused on the maturation of TLR expression during the early postnatal period in preterm newborns. Therefore, the existing information does not allow us to understand this important issue, which is whether the TLR system in preterm newborns is able to develop to an adequate level over the first few months after birth.

Our second and third major findings suggest that the blood monocytes of preterm newborns display a rapid increase in TLR2 and TLR4 surface expression during the first few weeks of life, whereas their response in terms of LPS-induced cytokine production does not improve. Therefore, it appears that the neonate monocytes have sufficient expression of TLR2 and TLR4 to respond to bacterial insult during this early postnatal period, but they remain immature with respect to LPS-induced cytokine production functionality. The exact mechanism by which this dissociation between the postnatal development of TLR expression and cytokine production functionality occurs remains unclear. A similar situation is found when monocytes are collected from full-term neonates at birth; these display a normal level of TLR 4 expression, but they also show reduced cytokine responses to LPS, as compared with monocytes from adults $(5,9,17,27,28)$. One possible explanation of this situation is that certain inhibitory molecules, such as adenosine that is present in the plasma, may suppress the LPS-induced cytokine responses of monocytes in these neonates $(4,29)$. However, this possibility is unlikely to be the case in our study because the monocytes remained hyporesponsive with respect to LPS-induced TNF- $\alpha$ and IL-8 production after 3 or even $5 \mathrm{~d}$ of culture (Figure 4). The other possibility is that the hyporesponsiveness of monocytes to LPS is a result of impaired TLR signaling, which may result from a reduced expression of various regulatory proteins including CD14 and the myeloid differentiation antigen $88(5,6,9,27)$. In support of this, it has been found that monocytes collected at birth from preterm newborns indeed do display reduced expression of myeloid differentiation antigen 88 and deficiency in TLR-mediated signaling (5). Whether these regulatory proteins and TLR signaling remain undeveloped over the first few months after birth in preterm newborns will be the subject of future studies. It is also worth noting that premature newborns with early-onset sepsis display high plasma levels of certain cytokines such as IL-6 and IL-8, which possess diagnostic values $(30,31)$. This observation seems to contradict our finding regarding reduced cytokine responses of monocytes to LPS in vitro. The discrepancy can be explained by the fact that the plasma cytokines in these newborns also encompass contributions from other blood cells $(12,32)$ and other tissues $(31)$.

Furthermore, we have shown that the level of expression of TLR2 (Figure 2b) and TLR4 (Figure 2c) by monocytes and the LPS-induced increases in TNF- $\alpha$ and IL- 8 production by monocytes (Figure 5) are positively correlated with the gestational age of preterm newborns. These results are generally in agreement with the observations from previous reports $(5,10,11)$. It is interesting to note that the correlations regarding TLR2 and TLR4 expression are superior to those regarding LPS-induced cytokine production. Moreover, this appears to support the dissociation of the development of TLR expression from that of cytokine production functionality, except for the fact that the changes occur during the gestational period. It is also intriguing to note that the speed of the increase in TLR2 and TLR4 expression over the gestational period (Figure 1) seems to be slower than over the early postnatal period (Figure 3). This rapid increase in TLR2 and TLR4 expression during the first few months after birth is likely to be a result of both the removal of endogenous inhibitory factors and the acquisition of exogenous stimulatory factors (4). 
In this study, the strength of the serial measurements of TLR expression and cytokine production is that we could follow the developmental progress over the study period in the same but separate cohorts of preterm newborns. However, due to ethical limitations, we could obtain blood monocytes only when blood sampling was required based on clinical considerations. As a consequence of this limitation, the number of measurements carried out on our subjects varied. A second limitation is that, under the institutional review board guidance, our regular interval of blood sampling was every 2 wk. For this reason, we could not perform series measurements at shorter intervals. A third limitation is that we were unable to study the cytokine responses to the TLR2 agonist because insufficient blood cells were collected from the preterm newborns in this study.

In conclusion, regardless gestational age, the monocytes of preterm newborns rapidly develop the surface expression of TRL2 and TLR4 during the first few months of life, whereas their LPS-induced cytokine production functionality remains immature. The current findings are important to our understanding of how the innate immune system of these newborns changes during this early postnatal period and how it responds to a bacterial infection.

\section{METHODS}

\section{Study Populations}

The study was approved by the institutional review board of Cathay General Hospital (institutional review board approval number: CT9855), and informed consent was obtained from the adult subjects and the parents of the newborns. Three study populations consisting of 62 preterm newborns, 93 healthy full-term newborns, and 17 adult healthy volunteers were included in this study. The neonates enrolled for the studies of TLR expression and LPS-induced cytokine production were admitted to the Cathay General Hospital, Taipei, Taiwan, during separate periods, 2006-2008 and 2009-2010, respectively. The exclusion criteria for the enrollment of neonates were (i) neonates who displayed evidence of major congenital malformations, (ii) neonates who had received immunotherapy, and (iii) neonates whose mothers had an infection before delivery. The neonates included in the current study were delivered spontaneously or by cesarean section without a history of infection during the mother's pregnancy or any clinical signs of infection at delivery. Preterm newborns were checked for infection by standard laboratory diagnosis and by placenta histology to rule out chorioamnionitis. Histological chorioamnionitis was defined as diffuse infiltration or aggregation of polymorphonuclear leukocytes in at least one high-power field of the chorioamnion plate (33). Newborns with any positive pathological result were excluded. During the postnatal period, the peripheral blood of the preterm infants was collected every 2 wk when a routine blood test was required.

\section{Blood Samples}

The cord blood of all infants was obtained from the placental side of the umbilical vein immediately (sooner than $5 \mathrm{~min}$ ) after delivery of the placenta. The peripheral blood of the preterm infants during the postnatal stage was obtained from the radial artery. The peripheral blood of the adults was obtained from the cephalic vein. The blood samples were collected in heparinized syringes and processed within $2 \mathrm{~h}$ after collection. Specifically, the heparinized blood was layered onto a Ficoll-Hypaque gradient, and the peripheral blood mononuclear cell layer was collected. The peripheral blood mononuclear cell solution was subjected to hypotonic lysis to remove any red blood cells that might be present and was then washed three times with phosphate-buffered saline buffer without magnesium or calcium; this was followed by resuspension in $2 \%$ bovine serum albumin solution.

\section{Immunofluorescence Staining}

Surface staining of TLR2 and TLR4 was carried out by a method described previously (34). Briefly, $50-\mu$ l peripheral blood mononuclear cell solution was incubated with either 10- $\mu$ l antihuman TLR2 monoclonal antibody $(0.05 \mathrm{mg} / \mathrm{ml}$, phycoerythrin-labeled, clone TL2.1; eBioscience, San Diego, CA) or 10- $\mu$ l antihuman TLR4 monoclonal antibody $(0.1 \mathrm{mg} / \mathrm{ml}$, phycoerythrin-labeled, clone HTA125; eBioscience). To detect monocytes, the cells were additionally stained with anti-CD14 monoclonal antibody $(25 \mathrm{mg} / \mathrm{ml}$ fluorescein isothiocyanate; Becton Dickinson, San Jose, CA). Control cells were stained with an isotype antibody (phycoerythrin or fluorescein isothiocyanate-labeled mouse immunoglobulin G2a; Becton Dickinson). The cells were incubated on ice for $30 \mathrm{~min}$ and subsequently washed with phosphate-buffered saline buffer twice. In the analysis of flow cytometry (FACScan; Becton Dickinson), the CD14positive monocytes were gated to separate them from other cell populations (e.g., lymphocytes and granulocytes) based on cell size and granularity (35). The purity of monocytes (>99\%) in the gated CD14-positive cells was evaluated by fluorescent staining with monoclonal antibodies of cell markers for other cell types and fluorescence-activated cell sorting analysis. The expression of TLR2 and TLR4 on the gated CD14-positive monocytes was then measured by flow cytometry, which analyzed $4 \times 10^{6} \mathrm{cells} / \mathrm{ml}$. In the dot plot of the flow cytometric analysis, events accumulated in the upper right quadrant of the panel are considered to represent CD14-positive cells (monocytes) with surface expression of either TLR2 or TLR4. For each analysis of the expression of TLR2 or TLR4, the quadrant of the plot was set based on the nonspecific staining plot using isotype immunoglobulin $\mathrm{G}$.

\section{RNA Isolation and Real-Time PCR}

Total RNA was isolated from the blood monocytes using an RNeasy minikit (Qiagen, Valencia, CA), as described in detail previously (34). Briefly, the isolated RNA was reverse-transcribed to cDNA using SuperScript First-Strand (Invitrogen, Carlsbad, CA). Quantitative real-time PCR was conducted for TLR2 and TLR4 with glyceraldehyde-3-phosphate dehydrogenase being used as an internal control. The TLR2, TLR4, and glyceraldehyde-3-phosphate dehydrogenase primers and probes were obtained from Applied Biosystems (Carlsbad, CA). The primers were for the fluorescence-labeled TAQMan probe system (FAM-MGB; Applied Biosystems). The real-time PCR amplification was performed on a RG-3000 system (Corbett, Chicago, IL). For the quantitative evaluation of gene expression, the TLR2 and TLR4 mRNA levels were normalized to the glyceraldehyde3-phosphate dehydrogenase mRNA.

\section{Measurements of LPS-Induced Cytokine Production}

The CD14-positive cells in peripheral blood mononuclear cells were magnetically labeled with CD14 MicroBeads (Miltenyi Biotec, Auburn, CA) and were passed through LS columns according to the manufacturer's instructions (Miltenyi Biotec). The purity of monocytes (95-98\%) was evaluated by fluorescent staining with CD14phycoerythrin monoclonal antibody and fluorescence-activated cell sorting analysis. After purification, blood monocytes were immediately subjected to culturing for 0,3 , and $5 \mathrm{~d}$ in cell culture medium (RPMI 1640; Life Technologies, Grand Island, NY). These cells were then stimulated with $10 \mathrm{ng} / \mathrm{ml}$ of LPS (Escherichia coli O55:B5; Calbiochem, La Jolla, CA) for $24 \mathrm{~h}$. Then the concentration of TNF- $\alpha$ and IL-8 in the cell culture supernatants was measured by commercially available enzyme-linked immunosorbent assay kits (R\&D system, Minneapolis, MN). The cutoff value for IL-8 using the kit is $10-400 \mathrm{pg} / \mathrm{ml}$ with a sensitivity of $<1 \mathrm{pg} / \mathrm{ml}$. The cutoff value for TNF- $\alpha a$ using the kit is $25-1,000 \mathrm{pg} / \mathrm{ml}$ with a sensitivity of $<5 \mathrm{pg} / \mathrm{ml}$. Duplicate measurements were performed for each sample.

\section{Statistical Analysis}

The distributions of the data sets were analyzed by the KolmogorovSmirnov test, and then normally and nonnormally distributed data sets were compared using the unpaired Student's $t$-test and MannWhitney test, respectively. Data sets from three groups or more with a normal distribution were evaluated by one-way ANOVA followed by the Bonferroni's method for multiple comparisons. Linear regression was used to obtain the correlation between TLR expression or 
cytokine level and gestational age. The statistical analysis was performed using the SPSS software package (SPSS for Windows, Release 12.0; SPSS, Chicago, IL). Data are expressed as means \pm SD. A $P$ value of $<0.05$ was considered significant.

\section{ACKNOWLEDGMENTS}

We thank Chia Chen Kuo for her technical support. The authors are grateful to Ralph Kirby, Department of Life Sciences, National Yang-Ming University, for his help with language editing.

\section{STATEMENT OF FINANCIAL SUPPORT}

This study was supported by the National Science Council of Taiwan grant NSC 98-2320-B-010-016-MY3, the Institute of Medical Research of the Cathay General Hospital grant MR9514, and a grant from Ministry of Education, Aim for the Top University Plan, Taiwan.

Disclosure: The authors declare no conflict of interest.

\section{REFERENCES}

1. Wynn JL, Levy O. Role of innate host defenses in susceptibility to earlyonset neonatal sepsis. Clin Perinatol 2010;37:307-37.

2. Corbett NP, Blimkie D, Ho KC, et al. Ontogeny of Toll-like receptor mediated cytokine responses of human blood mononuclear cells. PLoS ONE 2010;5:e15041

3. Clapp DW. Developmental regulation of the immune system. Semin Perinatol 2006;30:69-72.

4. Levy O. Innate immunity of the newborn: basic mechanisms and clinical correlates. Nat Rev Immunol 2007;7:379-90.

5. Sadeghi K, Berger A, Langgartner M, et al. Immaturity of infection control in preterm and term newborns is associated with impaired toll-like receptor signaling. J Infect Dis 2007;195:296-302.

6. Maródi L. Innate cellular immune responses in newborns. Clin Immunol 2006;118:137-44.

7. Fleer A, Krediet TG. Innate immunity: toll-like receptors and some more. A brief history, basic organization and relevance for the human newborn. Neonatology 2007;92:145-57.

8. Bessler H, Komlos L, Punsky I, et al. CD14 receptor expression and lipopolysaccharide-induced cytokine production in preterm and term neonates. Biol Neonate 2001;80:186-92.

9. Levy O, Zarember KA, Roy RM, Cywes C, Godowski PJ, Wessels MR. Selective impairment of TLR-mediated innate immunity in human newborns: neonatal blood plasma reduces monocyte TNF-alpha induction by bacterial lipopeptides, lipopolysaccharide, and imiquimod, but preserves the response to R-848. J Immunol 2004;173:4627-34.

10. Förster-Waldl E, Sadeghi K, Tamandl D, et al. Monocyte toll-like receptor 4 expression and LPS-induced cytokine production increase during gestational aging. Pediatr Res 2005;58:121-4.

11. Currie AJ, Curtis S, Strunk T, et al. Preterm infants have deficient monocyte and lymphocyte cytokine responses to group B streptococcus. Infect Immun 2011;79:1588-96.

12. Thornton NL, Cody MJ, Yost CC. Toll-like receptor $1 \frac{1}{2}$ stimulation induces elevated interleukin-8 secretion in polymorphonuclear leukocytes isolated from preterm and term newborn infants. Neonatology 2012;101:140-6.

13. Harju K, Glumoff V, Hallman M. Ontogeny of toll-like receptors Tlr2 and Tlr4 in mice. Pediatr Res 2001;49:81-3.

14. Hillman NH, Moss TJ, Nitsos I, et al. Toll-like receptors and agonist responses in the developing fetal sheep lung. Pediatr Res 2008;63:388-93.

15. Awasthi S, Cropper J, Brown KM. Developmental expression of Tolllike receptors- 2 and -4 in preterm baboon lung. Dev Comp Immunol 2008;32:1088-98.
16. Yerkovich ST, Wikström ME, Suriyaarachchi D, Prescott SL, Upham JW, Holt PG. Postnatal development of monocyte cytokine responses to bacterial lipopolysaccharide. Pediatr Res 2007;62:547-52.

17. Belderbos ME, van Bleek GM, Levy O, et al. Skewed pattern of Toll-like receptor 4-mediated cytokine production in human neonatal blood: low LPS-induced IL-12p70 and high IL-10 persist throughout the first month of life. Clin Immunol 2009;133:228-37.

18. Nguyen M, Leuridan E, Zhang T, et al. Acquisition of adult-like TLR4 and TLR9 responses during the first year of life. PLoS ONE 2010;5:e10407.

19. Burl S, Townend J, Njie-Jobe J, et al. Age-dependent maturation of Tolllike receptor-mediated cytokine responses in Gambian infants. PLoS ONE 2011;6:e18185.

20. Tulic MK, Hodder M, Forsberg A, et al. Differences in innate immune function between allergic and nonallergic children: new insights into immune ontogeny. J Allergy Clin Immunol 2011;127:470-78.e1.

21. Teran R, Mitre E, Vaca M, et al. Immune system development during early childhood in tropical Latin America: evidence for the age-dependent down regulation of the innate immune response. Clin Immunol 2011;138:299310 .

22. Chang YH, Yang SH, Wang TF, Lin TY, Yang KL, Chen SH. Complete blood count reference values of cord blood in Taiwan and the influence of gender and delivery route on them. Pediatr Neonatol 2011;52:155-60.

23. Armstrong L, Medford AR, Hunter KJ, Uppington KM, Millar AB. Differential expression of Toll-like receptor (TLR)-2 and TLR- 4 on monocytes in human sepsis. Clin Exp Immunol 2004;136:312-9.

24. Charrier E, Cordeiro P, Cordeau M, et al. Post-transcriptional down-regulation of Toll-like receptor signaling pathway in umbilical cord blood plasmacytoid dendritic cells. Cell Immunol 2012;276:114-21.

25. Miggin SM, O'Neill LA. New insights into the regulation of TLR signaling. J Leukoc Biol 2006;80:220-6.

26. Gibson A, Carney S, Wales JK. Growth and the premature baby. Horm Res 2006;65:Suppl 3:75-81.

27. Yan SR, Qing G, Byers DM, Stadnyk AW, Al-Hertani W, Bortolussi R. Role of MyD88 in diminished tumor necrosis factor alpha production by newborn mononuclear cells in response to lipopolysaccharide. Infect Immun 2004;72:1223-9.

28. Viemann D, Dubbel G, Schleifenbaum S, Harms E, Sorg C, Roth J. Expression of toll-like receptors in neonatal sepsis. Pediatr Res 2005;58:654-9.

29. Levy O, Coughlin M, Cronstein BN, Roy RM, Desai A, Wessels MR. The adenosine system selectively inhibits TLR-mediated TNF-alpha production in the human newborn. J Immunol 2006;177:1956-66.

30. Laborada G, Rego M, Jain A, et al. Diagnostic value of cytokines and C-reactive protein in the first 24 hours of neonatal sepsis. Am J Perinatol 2003;20:491-501.

31. Berner R, Niemeyer CM, Leititis JU, et al. Plasma levels and gene expression of granulocyte colony-stimulating factor, tumor necrosis factor-alpha, interleukin (IL)-1beta, IL-6, IL-8, and soluble intercellular adhesion molecule-1 in neonatal early onset sepsis. Pediatr Res 1998;44:469-77.

32. Peoples JD, Cheung S, Nesin M, et al. Neonatal cord blood subsets and cytokine response to bacterial antigens. Am J Perinatol 2009;26:647-57.

33. Wu HC, Shen CM, Wu YY, Yuh YS, Kua KE. Subclinical histologic chorioamnionitis and related clinical and laboratory parameters in preterm deliveries. Pediatr Neonatol 2009;50:217-21.

34. Shen CM, Lin SC, Niu DM, Kou YR. Labour increases the surface expression of two Toll-like receptors in the cord blood monocytes of healthy term newborns. Acta Paediatr 2009;98:959-62.

35. Holmes KL, Otten G, Yokoyama WM. Flow cytometry analysis using the Becton Dickinson FACS Calibur. Curr Protoc Immunol 2002; Chapter 5: Unit 5.4. 